\title{
Differential substrate subsidence of the EnviHUT project pitched extensive green roof
}

\author{
Klára Nečadová ${ }^{1, *}$, Petr Selník ${ }^{1}$, and Hana Karafiátová ${ }^{1}$ \\ ${ }^{1}$ Brno University of Technology, Faculty of Civil Engineering, Veveri 331/95, Brno, Czech Republic
}

\begin{abstract}
In primary phase of testing building physical characteristics of the EnviHUT project extensive and semi-intensive roofs with $30^{\circ}$ inclination occurred exceptional substrate subsidence. An extensive testing field with retaining geocell-system evinced differential subsidence of individual sectors after six months. Measured subsidence of installed substrate reached $40 \%$ subsidence compared to originally designed height (intended layer thickness). Subsequent deformation of geocell-system additionally caused partial slide of substrate to drip edge area. These slides also influenced initial development of stonecrop plants on its surface. Except functional shortages the aesthetical function of the whole construction is influenced by the mentioned problem. The stated paper solves mentioned issues in view of installation method optimization, selection and modification of used roof substrate and in view of modification of geometric and building installed elements retaining system arrangement. Careful adjustment of roof system geometry and enrichment of original substrate fraction allow full functionality from pitched extensive green roof setting up. The modification scheme and its substantiation is a part of this technical study output.
\end{abstract}

\section{Introduction}

In AdMaS sites of Brno University of Technology AdMaS there is ongoing longitudinal study of behaviour of different variants of vegetative roofs. The main test unit is the project EnviHUT, where were after 10 month of existence registered significant volume changes of substrates of extensive green roofs and geometric rearrangement of the restraint system. This paper is about evaluation and description of these two major defects in construction.

\subsection{Construction description}

\subsubsection{EnviHUT}

EnviHUT is designed as a small portable holiday building with container frame construction and roofed with pitched green roof with three variants of vegetation layer. Used building materials of individual enveloppe construction were chosen with respect to

\footnotetext{
* Corresponding author: necadovak@fce.vutbr.cz
} 
the requirements of building-physical measurement of new recycled or local natural materials and construction designs. The EnviHUT is self-sufficient independent object from the perspective of use of energy and its technological operation is provided with associated wind power station, solar roof panels and automated control battery unit [1].

EnviHUT is intentionally exposed to aggressive impact of climate, especially strong wind, therefore many North European design solutions and components were used in construction. At the same time this negative effect was turned into a benefit in the form of high-quality ventilation of ventilated spaces using the chimney effect [2].

The choice of natural and recycled building materials meets the needs of research of each team member. On the roof synthetic partly recycled roofing substrate and local natural soil are installed. Also a vegetation retention layer of recycled polyester bi-component developed by authors is installed.

Structural design in terms of temperature oscillation in the hot summer was taken into consideration. Based on the quantity of the soil $[3,4]$, rich vegetation, vegetation-associated retention panels [5] and the design of the roof with sufficient overlap the final design oscillation frequency of the temperature was set as 12 hours. With this proposal, in combination with a controlled ventilation on the north side, should be ensured optimum internal temperature environments and surfaces, without requiring the operation of energyintensive air conditioning units.

\subsection{Assessed test segments}

The first segment has structure formed from sheets of recycled PES with a thickness of $60 \mathrm{~mm}$, which form a vegetation-retention layer, also cellular capture system, which is filled with crushed substrate with the planned thickness of $120 \mathrm{~mm}$, and finally formed by vegetated sedum plants. This system represents a roof with poor vegetation.

The middle segment is based on the Swiss concept and represents a biodiversal roof alias a roof with rich vegetation. This composition is supported with vegetation retentionlayer boards made of recycled polyester 40 or $60 \mathrm{~mm}$ thick, on which is located a restraining system of a plate material and a reinforcement mesh. On this layer is stacked $180 \mathrm{~mm}$ of soil from excavation. For speeding up growth vegetation grass mats complemented by the seeds of surrounding plants (poppies, various grasses, camomile etc.) were used.

The last segment represents an Icelandic concept of pitched green roofs realization. On the vegetation-retention layer of different thickness are laid grass mats between which is installed reinforcing net and natural soil. The first two mats are laid with roots up and the last mat, which forms the surface structure, is laid with roots down. This way designed and implemented layer forms very resistant and stable system that can resist extreme weather.

Consolidation in the Nordic and semi-intensive biodiversity variant was successful. Slides in monitored area were not registered. Subsidence went equally in whole area and orientation.

\subsection{Vegetation retention layer}

Installation vegetation-retention plate with a total dimension of $1.2 \times 0.8 \mathrm{~m}$ was sticking this layer to a securing waterproofing layer in the longitudinal direction. (Longitudinal direction was chosen in order to reduce mutual joints of entire layer.) Surface of securing waterproofing layer had to be cleared off layers of polyethylene - burned down. The adhesive low-expansion polyurethane foam which was applied after 20 to $25 \mathrm{~cm}$ in the vertical direction across the width of the plate was used. The reason for using lowexpansion polyurethane foam was its higher mold resistance, limiting fungus growth in the 
connection and high adhesion to the connected surface. Glued mattresses were temporarily for 2 min weighted down so that the equalization occurred in their entire length and formation of joints there between them was reduced. The joint between the mattresses was not glued together in order to maintain uniform flow characteristics of the entire cross section of the layers in the structure. Details, corner and edge parts were then formed, so as to ensure homogeneity and integrity of layer [3].

Due to the different thickness of the used mats a model of the amount of water collected in monitored segments can be made [6]. On EnviHUT were used two types of mattresses, namely:

- Mattresses about $4 \mathrm{~cm}$ thick in the performance of $4000 \mathrm{~g} / \mathrm{m}^{2}$,

- Mattresses about $6 \mathrm{~cm}$ thick in the performance of $6000 \mathrm{~g} / \mathrm{m}^{2}$.

A thicker version was used on the whole area of the south side of the roof and at the ridge of the northern exposure with a width of $80 \mathrm{~cm}$. On the rest area was glued a mattress with a smaller retention capability. After gluing this layer was left for 12 hours without any further intervention. On this layer the installation of the catching system, the substrate and the layers of vegetation followed.

\subsection{Catching system and planting of vegetation}

The installation of geocells net was anchored to an additional frame element at the ridge and on the sides of the roof. Partially ( $20 \%$ of the length of the ridge) is the net also folded over the ridge. Subsequently, the area was backfilled with original roof substrate (by a Czech producer) in direction from the ridge to the eaves.

This installation was not realized directly by the authors of the project. It was entrusted to the company, which realize vegetative roofs on a long-term basis.

The chosen form of installation did not allow more efficient compaction. After installation that part showed large volume changes caused by uneven consolidation of the dependent variable shape of each connected segment. Since the installation was made before the dormancy period of planted vegetation, it has not grown fast. The contact surface was exposed to mild winter conditions in the following months. At the end of the winter small surface landslides were observed. Caused landslides were observed on both of installed exposures (NNE) - (SSW). At least 5 of the 25 applied packages $(40 \mathrm{~kg})$ contained uncrushed expanded clays and shales.

\section{Measurement conditions}

The main test surface is gabled green roof with an inclination of $30^{\circ}$ with NNE - SSW orientation and testing segment with the size of $2.4 \times 2.5 \mathrm{~m}$. Gabled roof structure has an inclination of $30^{\circ}$ and is divided into three sections.

Installation of the roof took place at the end of September and during October 2015 with adapted vegetation-retention plate of polyester fibers and clusters with the performance of $4000 \mathrm{~g} / \mathrm{m}^{2}$ at a height of $4 \mathrm{~cm}$ and $6000 \mathrm{~g} / \mathrm{m}^{2}$ at a height of $6 \mathrm{~cm}$. Subsequent winter was very mild with little precipitation, without extreme freezing season. The temperature in the monitored period fell only one day under the designed $-12{ }^{\circ} \mathrm{C}$. The only one month with a negative average temperature was January $-1.94{ }^{\circ} \mathrm{C}$. Not divided installed geocells were measured in the vertical direction $v$ and horizontal direction $h$. Subsequently, the mutual evaluation of the measurement dimensions individually to the whole were done. Divided cells were not included in this evaluation. Accuracy of measurement was set to $\pm 5 \mathrm{~mm}$, what is twice the width of the installed geocells net. Installation average dimension $v_{i} x h_{i}$ was measured as $(40 \pm 0.5) \times(40 \pm 0.5) \mathrm{cm}$. 
The aim of the evaluation is to define the degree of the creep after the consolidation of the structure and also to evaluate the question of uniformity subsidence of studied element.

The measurement results from the May 30th, 2016 were systematically noted in Table 1 for the south side and in Table 2 for the north side. The table is not the standard form of record but more chart from which the final forming of entire restraint geo-cell system demonstrated in Figure 1 can be seen. Some cells were not depressed on the surface. These cells could not be measured without disturbing the existing roof surface. In the table, this condition is marked with the term cov as covered. Some cells were so deformed that it was impossible to measure monitored dimension. These cells are in table marked with the term dam as damaged.

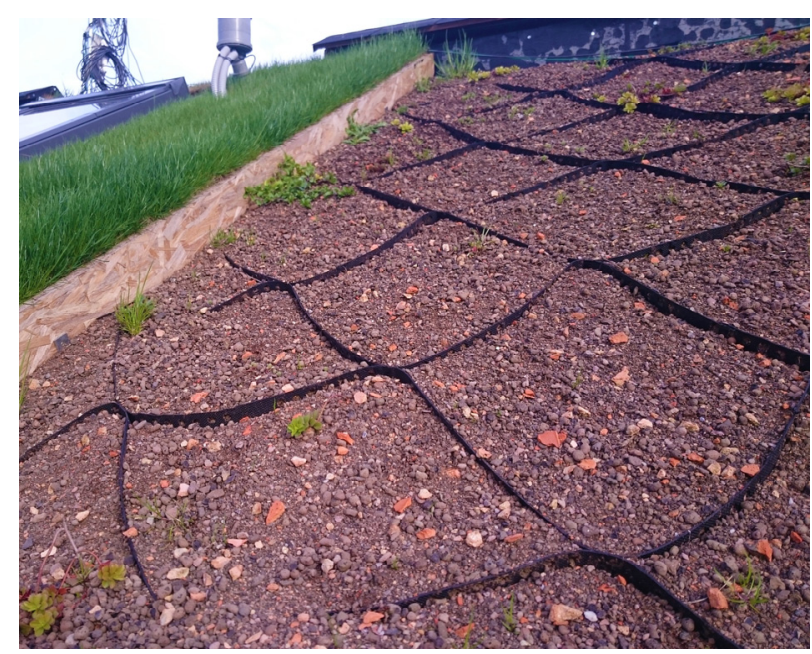

Fig. 1. A surface at eaves on the northern side.

\section{Results}

Table 1. Final shaping of geocells on the southern exposure.

\begin{tabular}{|c|c|c|c|c|c|c|c|c|c|c|c|c|}
\hline \multicolumn{13}{|c|}{ Final shaping of geocells on the southern exposure } \\
\hline \multirow{2}{*}{\multicolumn{3}{|c|}{$[\mathrm{cm}]$}} & \multicolumn{10}{|c|}{ Vertical line } \\
\hline & & & \multicolumn{2}{|c|}{ I } & \multicolumn{2}{|c|}{ II } & \multicolumn{2}{|c|}{ III } & \multicolumn{2}{|c|}{ IV } & \multicolumn{2}{|c|}{$\mathrm{V}$} \\
\hline \multirow{10}{*}{ 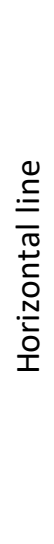 } & J & & & v & & & & & & & & \\
\hline & \multirow{2}{*}{$\mathrm{H}$} & I & 41 & 51 & & 52 & & 54 & & & & \\
\hline & & & 45 & 53 & cov & 48 & 54 & 44,5 & 53 & & cov & \\
\hline & $\mathrm{F}$ & & 54 & $\operatorname{cov}$ & cov & 51 & 44,5 & 49 & 38,5 & 44 & cov & \\
\hline & & $F$ & 41,5 & $\operatorname{cov}$ & 48,5 & 45,5 & 51,5 & 50 & 50 & 53,5 & 40 & \\
\hline & \multirow{2}{*}{ D } & L & 54 & 47 & 50,5 & 48,5 & 48,5 & 48 & 48,5 & 46,5 & 46,5 & 49 \\
\hline & & C & 42 & 52 & 47 & 50 & 43,5 & 50 & 47,5 & 52,5 & dam & 47,5 \\
\hline & \multirow{3}{*}{ B } & & 51 & 42 & 51,5 & 42,5 & 55 & 44,5 & 50 & 51,5 & dam & \\
\hline & & A & 46,5 & 55,5 & 38,5 & 54 & 41 & 53,5 & 46 & 43,5 & 52,5 & \\
\hline & & $\pi$ & 48,5 & & 58,5 & & 55,5 & & 46 & & 35,6 & \\
\hline
\end{tabular}


Table 2. Final shaping of geocells on the northern exposure.

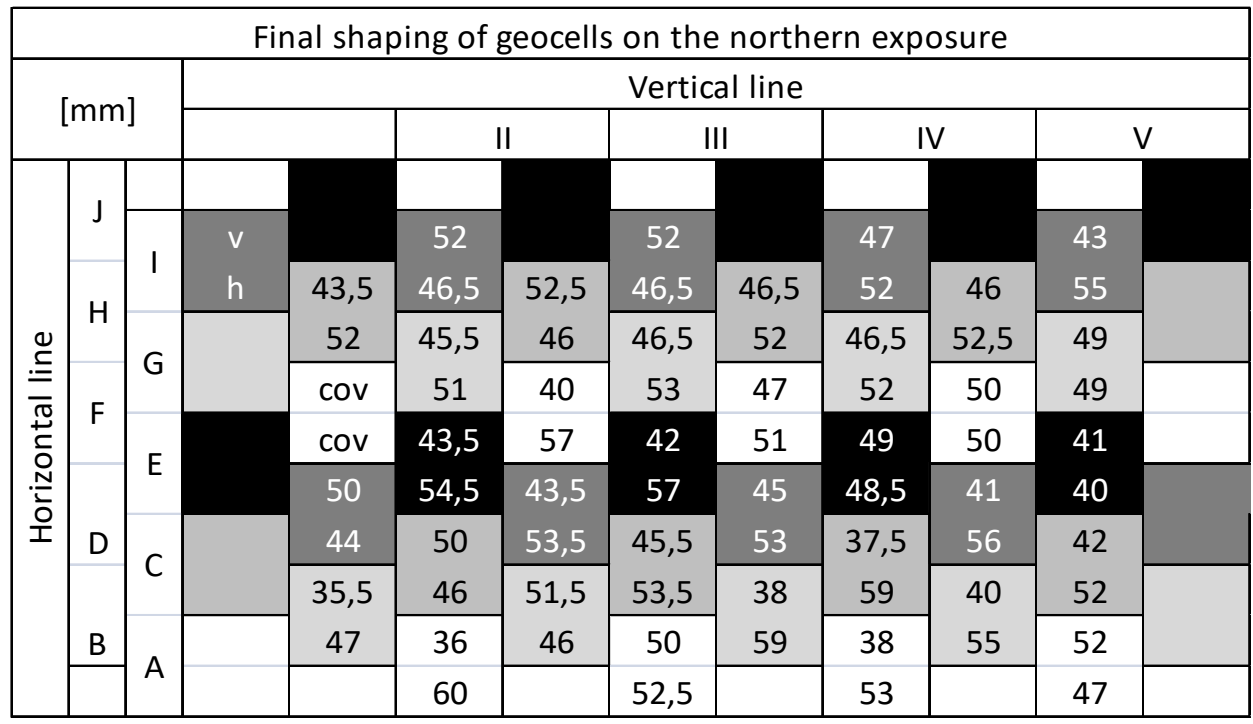

\subsection{Measurement comment:}

\subsubsection{The South side}

O The diameter of the unit $\mathrm{v}=46.95 \mathrm{~cm} ; \mathrm{h}=48.10 \mathrm{~cm}$,

- Series G - misalignment in subsidence 1 to 4 in the horizontal direction,

- Series E - misalignment in vertical direction E1 to E2 and also E4 and E5,

- Series D - balanced settlement,

- Series B - B4 significant vertical deformation against the line and also the uneven settlement to horizontal direction,

- Series A - a drop in columns A2 followed by a significant horizontal deformation A2 and $\mathrm{A} 3$,

- Sum of columns $2,3,4(194 ; 190 ; 196.5 \mathrm{~cm})$ is about $18.5 \mathrm{~cm}$ different compared to column $1(175 \mathrm{~cm})$,

- The sum of the rows E, D, A $(248,252,244 \mathrm{~cm})$ - uniform subsidence in the horizontal direction relative to the whole.

\subsubsection{The North side}

- The diameter of the unit $\mathrm{v}=45,09 \mathrm{~cm} ; \mathrm{h}=51,49 \mathrm{~cm}$,

○ I2, I3 are vertically mutually equivalent; I5 is shifted against previous units,

- The last column G Series - partly compensates changes caused by the series I,

- Series D and column 1 is significantly deformed to the whole line,

- The most significantly deformed is unit $\mathrm{C} 4$ and its surroundings,

- A2 and C4 is the most deformed at all,

- B3 and B2, F2 and F3 - is misalignment offsetting rows B and F,

- Sum of columns $3,4(236,218 \mathrm{~cm})$ is different from the outer column $2,5(227 \mathrm{~cm})$,

- The horizontal sum of rows A, B, C, D, E, G, H, I (212.5; 207; 210.5; 206.5; 200; 205; $202.5 ; 200)$ - Part E up to I is uniform in horizontal plane, followed by an increase in the ranks of $\mathrm{D}$ and following similar lines a to $\mathrm{C}$. 


\subsection{Proposed changes of the installation procedure}

The substrate is a key aspect that the most affects the stability of the final installation. Especially for substrates with a component of expanded clays and shales. Within supply of these materials must be strictly checked actually delivered substrate and verify the main required installation parameters - these parameters are mainly grain composition and crushing level of solid particles. Here is the critical point of substrate purchase and application. Some substrates are limited by technological possibilities of mixing and subsequent packaging according to the forms of distribution. Unsuitable packaged substrates with less crushed component, which is getting to the substrates by mixing light particles and by insufficient output control, in the realization must be expected and consistently conduct its own process control of applied material. The unfavorable combination of those processes can result in landslides as well as test implementation demonstrated in Figure 3.

This problem could be compensated by own adjustment of the substrate composition, especially to enrich provided substrate with the other bigger fractions. This process was consulted with experts from the BOKU who recommend to enrich the existing installation with stabilizing binding fraction (16-32 mm). Mentioned fraction would not be no longer a part of roofing substrates according to FLL Guidelines, but this is correction of an existing layer. The reason is to create a granularity step curve, so that it can lead to the formation of bonds which prevent landslides on pitched roofs. This corrective application is the most effective measure from the perspective of the authors and collaborating institutions.

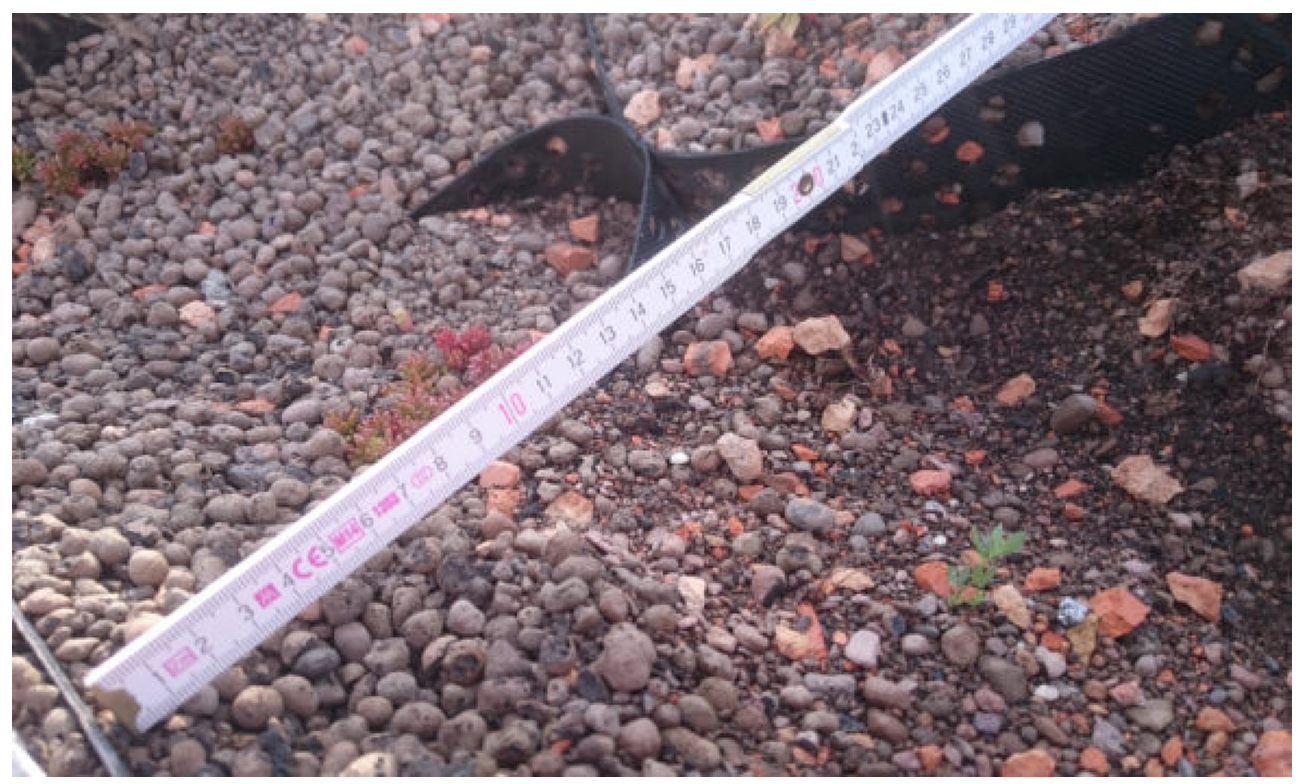

Fig. 2. A landslide at the eaves on the south side.

\section{Conclusion}

Expansion of pitched green roofs applications is connected to the quality of implementation examples that can reach potential customers. Aesthetic and functional defects, which are monitored on a test object, must be preceded by strict implementation of the technological process. The mentioned study points out the critical points of used forms of implementation. 
Due to large deformations of individual geocell and the whole restraint system the team of authors recommends to change the size of the grid applied geocells from $40 \times 40$ (H x D) to half in both directions. Individual partitions of geocells are overburdening with the substrate. In conjunction joints it consequently comes to dependent changing of the entire grid of restraint system. Defect can be caused also by increased local weather effects on a small contact area. This leads, in combination with the already discussed problem of substrate supply, to landslides. These landslides secondarily damage the geometry of system and do not allow continuous development of surface vegetation. The exposed areas are degraded by wind erosion and partly also rain helps to float the substrate. This erosin on the tested object is enhanced by the large amount of installed spherical expanded beads, which successively reach the contact surface. Here are due to its low weight affected with wind and accumulate at the eaves of the roof.

Corection of such roof is very expensive particularly in terms of time and it would be possible to avoid it with strict control of used substrate before installation. Declared material supply in our case did not match the required characteristics in $20 \%$ of its volume. Especially crushing expanded beads was critical.

The damaged layer will be repaired in October 2016 and observe with the same geometry of the restraint system. Further measurements with the same parameters will be done before this modification.

Authors would like to express their appreciation and thanks to Dr. Bernhard Scharf and Dr. Ulrike Pitha, their research team and the support from the Universität für Bodenkultur Wien and to Dr. David Bečkovský and Dr. Martin Mohapl from the Brno University of Technology.

This paper was completed under project no. LO1408 "AdMaS UP - Advanced Materials, Structures and Technologies", supported by the Ministry of Education, Youth and Sports under the National Sustain- ability Programme I and under the Project FAST-S-16-3345 supported by Ministry of Education, Youth and Sports under "Specific University Research".

\section{References}

1. T. Pereira, et al., The $1^{\text {st }}$ European Urban Green Infrastructure Conference (Institute for Sustainable Engineering, University of Palermo, Vienna, Austria, 2015)

2. G. Kotsiris, A. Androutsopoulos, E. Polychroni and P. A. Nektarios, Energy and Buildings 45, 240-249 (2012)

3. T. Emilsson, Ecological Engineering 33(3-4), 265-277 (2008)

4. K. L. Getter, D. B. Rowe, HortScience 44(2), 401-407 (2009)

5. J. Mentes, D. Raes, M. Hermy, Landscape and Urban Planning 77, 217-226 (2006)

6. N. D. Vanwoert, D. B. Rowe, J. A. Andresen, C. L. Rugh and L. Xiao, HortScience 40(3), 659-664 (2005) 